\title{
Influence of Machine Topology and Cross-Coupling Magnetic Saturation on Rotor Position Estimation Accuracy in Extended Back-EMF Based Sensorless PM Brushless AC Drives
}

\author{
Z. Q. Zhu, Y. Li, D. Howe, C. M. Bingham, and D. Stone \\ Department of Electronic and Electrical Engineering, University of Sheffield, Sheffield S1 3JD, UK
}

\begin{abstract}
The influence of the machine topology and $d q$-axis cross-coupling on the rotor position estimation error in an extended back-EMF based sensorless brushless AC drive is investigated by both finite element analysis and experimentally on four brushless AC machines having different rotor topologies, viz. interior circumferentially magnetized, interior radially magnetized, surface-mounted, and inset magnets. The $d$ - and $q$ axis apparent self- and mutual-inductances, $L_{d}, L_{q}, L_{d q}$ and $L_{q d}$, are predicted by finite element analysis for various $d$ - and $q$-axis currents. The error in the estimated rotor position of the four machines is investigated and compared when (a) the influence of magnetic saturation is neglected, (b) only the influence of the $q$ axis current on $L_{q}$ is considered, but $d q$-axis cross-coupling magnetic saturation is neglected, and (c) the influence of $d q$-axis cross-coupling magnetic saturation is taken into account. It is shown that the error is more strongly influenced by the $q$-axis current/permeance than the $d$-axis current/permeance, since the $d$-axis current does not distort the symmetrical field distribution about the $d$-axis, and that $d q$-axis cross-coupling magnetic saturation can significantly affect the accuracy of the rotor position estimation. However, by introducing an apparent mutual winding inductance in the extended back-EMF based sensorless method, the error in all four machines under consideration is reduced significantly, to a similar level to that which results with surface-mounted magnet machines.
\end{abstract}

Keywords- brushless AC motor, back-EMF, cross-coupling, permanent magnet, sensorless

\section{INTRODUCTION}

In order to improve the system reliability and reduce cost, sensorless control techniques are desirable for permanent magnet (PM) brushless AC (BLAC) drives. Back-EMF based techniques are simple and widely used, but are only appropriate for higher speed operation [1][2]. On the other hand, signal injection based schemes are appropriate at standstill and for low speed operation [3]. Hence, it is common to employ a hybrid sensorless approach, which uses a combination of signal injection and back-EMF methods [4].

For machines which exhibit magnetic saliency, an extended back-EMF sensorless method has been developed [1][2], which makes the impedance matrix of the $d q$-axis voltage equations symmetrical by combining the $d$-axis inductance term with the EMF term. However, in [1], magnetic saturation was neglected, and the $q$-axis apparent inductance was assumed to be constant. The influence of magnetic saturation on the $q$-axis inductance due to the q-axis current was subsequently considered in [2][4]. However, the influence of $d q$-axis cross-coupling magnetic saturation, which PM BLAC machines [5] usually exhibits to a greater or lesser degree, was not considered in [1][2][4]. It was, however, accounted for in [6] which highlighted its influence on the accuracy of the estimated rotor position. However, the investigation in [6] was restricted to a single interior permanent magnet machine.

In this paper, the influence of the machine topology on the accuracy of the estimated rotor position in an extended backEMF based sensorless brushless ac drive is investigated, with particular reference to $d q$-axis cross-coupling magnetic saturation. Four machines which have the same stator, equipped with an overlapping winding, but different rotors, viz. with interior circumferentially magnetized, interior radially magnetized, surface-mounted, and inset magnets, are considered.

The improved extended back-EMF sensorless method which accounts for cross-coupling magnetic saturation is briefly described in Section II, whilst the $d$ - and $q$-axis apparent self- and mutual-inductances, $L_{d}, L_{q}, L_{d q}$ and $L_{q d}$, are predicted for various $d$ - and $q$-axis currents in the four machine topologies in Section III. In Section IV, the error in the estimated rotor position of the four machines is investigated by both finite element analysis and experimentally, when (a) the influence of magnetic saturation is neglected, (b) only the influence of the $q$-axis current on the $q$-axis self-inductance is considered, with the influence of $d q$ axis cross-coupling magnetic saturation neglected, and (c) with the influence of $d q$-axis cross-coupling magnetic saturation considered.

\section{EXTENDED BACK-EMF BASEd SENSORLESS CONTROL Method ACCOUNTING FOR CROSS-COUPLing MAGNETIC SATURATION}

The $d q$-axis voltage equations of a BLAC motor in the rotor reference frame are: 


$$
\left[\begin{array}{l}
v_{d} \\
v_{q}
\end{array}\right]=\left[\begin{array}{cc}
R_{s} & 0 \\
0 & R_{s}
\end{array}\right]\left[\begin{array}{l}
i_{d} \\
i_{q}
\end{array}\right]+\left[\begin{array}{l}
d \psi_{d} / d t-\omega_{r} \psi_{q} \\
d \psi_{q} / d t+\omega_{r} \psi_{d}
\end{array}\right]
$$

where $R_{s}$ is the phase resistance, $v_{d}, v_{q}, i_{d}, i_{q}, \psi_{d}$, and $\psi_{q}$ are the $d$ - and $q$-axis voltages, currents, and flux-linkages, respectively, and $\omega_{r}$ is the electrical angular velocity of the rotor.

However, during steady-state and slowly changing operational conditions, the time derivative of the $d q$-axis fluxlinkages, i.e. $d \psi_{d} / d t \approx 0$ and $d \psi_{q} / d t \approx 0$, can be neglected and the voltage equations become:

$$
\left[\begin{array}{l}
v_{d} \\
v_{q}
\end{array}\right]=\left[\begin{array}{cc}
R_{s} & 0 \\
0 & R_{s}
\end{array}\right]\left[\begin{array}{l}
i_{d} \\
i_{q}
\end{array}\right]+\left[\begin{array}{c}
-\omega_{r} \psi_{q} \\
\omega_{r} \psi_{d}
\end{array}\right]
$$

$\psi_{d}$ and $\psi_{q}$ vary non-linearly with the $d$ - and $q$-axis currents, due to the influence of magnetic saturation, and can be written as [5]:

$$
\left\{\begin{array}{l}
\psi_{d} \equiv \psi_{d}\left(i_{d}, i_{q}\right)=L_{d} i_{d}+L_{d q} i_{q}+\psi_{m} \\
\psi_{q} \equiv \psi_{q}\left(i_{d}, i_{q}\right)=L_{q} i_{q}+L_{q d} i_{d}
\end{array}\right.
$$

where $\psi_{m}$ is the flux-linkage due to the permanent magnets, $L_{d}$, $L_{q}, L_{d q}$, and $L_{q d}$ are the $d$ - and $q$-axis apparent $d q$-axis inductances and mutual-inductances, respectively. However, conventional extended back-EMF methods [1][2] neglect the influence of cross-coupling magnetic saturation between the $d$ and $q$-axes.

Equation (3) can be substituted into (2) and the $d q$-axis voltage equations can be re-written as:

$$
\left[\begin{array}{c}
v_{d} \\
v_{q}
\end{array}\right]=\left[\begin{array}{cc}
R_{s}-\omega_{r} L_{q d} & -\omega_{r} L_{q} \\
\omega_{r} L_{d} & R_{s}+\omega_{r} L_{d q}
\end{array}\right]\left[\begin{array}{c}
i_{d} \\
i_{q}
\end{array}\right]+\left[\begin{array}{c}
0 \\
\omega_{r} \psi_{m}
\end{array}\right]
$$

In order to make the impedance matrix symmetrical, the $d$ axis inductance term is combined with the EMF term, i.e.:

$$
\left[\begin{array}{l}
v_{d} \\
v_{q}
\end{array}\right]=\left[\begin{array}{cc}
R_{s}-\omega_{r} L_{q d} & -\omega_{r} L_{q} \\
\omega_{r} L_{q} & R_{s}-\omega_{r} L_{q d}
\end{array}\right]\left[\begin{array}{l}
i_{d} \\
i_{q}
\end{array}\right]+\left[\begin{array}{c}
0 \\
E_{e x}
\end{array}\right]
$$

where $E_{e x}$ is the extended back-EMF, viz.:

$$
E_{e x}=\omega_{r} \psi_{m}+\left(\omega_{r} L_{d}-\omega_{r} L_{q}\right) i_{d}+\left(\omega_{r} L_{d q}+\omega_{r} L_{q d}\right) i_{q}
$$

Since the actual rotor position, $\theta_{r}$, is not available with sensorless control, (5) is required to be transformed into the estimated $d q$-axis reference frame, $\theta_{r}^{e}$.

$$
\left[\begin{array}{c}
v_{d}^{e} \\
v_{q}^{e}
\end{array}\right]=\left[\begin{array}{cc}
R_{s}-\omega_{r} L_{q d} & -\omega_{r} L_{q} \\
\omega_{r} L_{q} & R_{s}-\omega_{r} L_{q d}
\end{array}\right]\left[\begin{array}{c}
i_{d}^{e} \\
i_{q}^{e}
\end{array}\right]+\left[\begin{array}{c}
E_{e x d} \\
E_{e x \underline{q}}
\end{array}\right]
$$

where $v_{d}^{e}, v_{q}^{e}, i_{d}^{e}, i_{q}^{e}, E_{e x_{-} d}$ and $E_{e x_{-} q}$ are the $d$ - and $q$-axis voltages, currents, and extended back-EMFs in the estimated rotor reference frame, where:

$$
\begin{aligned}
& E_{e x \_d}=E_{e x} \sin \Delta \theta \\
& E_{e x-q}=E_{e x} \cos \Delta \theta
\end{aligned}
$$

and $\Delta \theta=\theta_{r}{ }^{e}-\theta_{r}$ is the error in the estimated rotor position. As will be evident from (8), the error can be calculated from $E_{\text {ex }} d$, and $E_{e x \_q}$, i.e.:

$$
\begin{aligned}
& \left\{\begin{array}{l}
E_{e x_{-} d}=v_{d}^{e}-R_{s} i_{d}^{e}+\omega_{r}\left(L_{q} i_{q}^{e}+L_{q d} i_{d}^{e}\right) \\
E_{\text {ex_q }}=v_{q}^{e}-R_{s} i_{q}^{e}-\omega_{r}\left(L_{q} i_{d}^{e}-L_{q d} i_{q}^{e}\right)
\end{array}\right. \\
& \Delta \theta=\theta_{r}^{e}-\theta_{r}=\arctan \left(E_{\text {ex_d }} / E_{\text {ex } q}\right) \approx E_{\text {ex_d }} / E_{\text {ex_q }}
\end{aligned}
$$

The estimated rotor position error, $\Delta \theta$, which is calculated from (10), can then be used to correct the estimated rotor position, $\theta_{r}^{e}$, and speed, $\omega_{r}^{e}$. Clearly, when $E_{e x d}$ is forced to zero in the extended back-EMF sensorless control scheme, the estimated rotor position is equal to the actual rotor position, i.e., $\Delta \theta=0$.

In (4), the $q$-axis flux-linkage is represented by the $q$-axis apparent self-inductance $L_{q}$ and the $d q$-axis mutual-inductance $L_{q d}$, i.e., $\psi_{q}=L_{q} i_{q}{ }^{e}+L_{q d} i_{d}^{e}$, where $L_{q}\left(i_{q}\right)$ is a function of $i_{q}$ and $L_{q d}\left(i_{d}, i_{q}\right)$ is a function of both $i_{d}$ and $i_{q}$. It will be noted from (9) that the $d$-axis apparent self-inductance $L_{d}$ and the $d q$-axis mutual-inductance $L_{d q}$ do not affect $E_{e x_{-} d}$ and $E_{e x_{-} q}$. Hence, their accuracy will not influence the accuracy of the estimated rotor position.

In practice, the winding resistance $R_{s}$ varies with the winding temperature, and may, therefore, affect the rotor position estimation accuracy, since, as can be seen from (9), if the value of $R_{s}$ is assumed to be at ambient temperature, e.g. $25^{\circ} \mathrm{C}$, the rotor position error would be $\Delta \theta=-\left[R_{s}(T)-R_{s}\left(25^{\circ}\right)\right] i_{d}^{e} / E_{e x_{-} q}$, where $T$ is the actual winding temperature. Further, since $E_{e x} q$ is generally dominated by the term $\omega_{r} \psi_{m}$, the error due to changes in the winding resistance depends on the rotor speed. However, in this paper, $R_{s}$ is assumed to be constant, since at high speed its influence on $E_{e x-q}$ will be small, whilst when $i_{d}{ }^{e}=0$ control is employed, it will not affect the accuracy of the rotor position estimation.

From (9), however, $L_{q}$ and $L_{q d}$ may have a significant influence on the accuracy the estimated rotor position. If $L_{q}$ is assumed to the constant and the $d q$-axis cross-coupling is neglected, i.e. $L_{q d}=0 \mathrm{mH}$, as was the case in [1], the resulting error in the estimated rotor position is:

$$
\Delta \theta=\left\{\left[L_{q}\left(i_{q}\right)-L_{q}\left(i_{q N}\right)\right] i_{q}^{e}+L_{q d}\left(i_{d}, i_{q}\right) i_{d}^{e}\right\} /\left(E_{e x_{-} q} / \omega_{r}\right)
$$

where $L_{q}\left(i_{q N}\right)$ is the constant apparent $q$-axis self-inductance at rated $q$-axis current.

If magnetic saturation on the $q$-axis and its variation with $q$ axis current is accounted for, but $d q$-axis cross-coupling is neglected, as was the case in [2], the error in estimated rotor position is:

$$
\Delta \theta=L_{q d} i_{d}^{e} /\left(E_{e x \_q} / \omega_{r}\right)
$$

\section{DQ-AXIS SELF- AND MUTUAL-INDUCT ANCES FOR DIFFERENT MACHINE TOPOLOGIES}

Four 3-phase, 6-pole, 18-slot, BLAC machines, equipped with the same overlapping stator winding and designed to produce the same torque in the constant torque operational mode but having different rotor topologies, viz. with interior circumferentially magnetized, interior radially magnetized, surface-mounted, and inset magnets [7], are considered, Fig. 1, 
the main design parameters being given in Table I. The stator is skewed by one slot-pitch and the winding is full-pitched. Figs. 2-5 show the magnetic field distributions which result with various $d q$-axis currents for the four machines. It can be seen that for all the machines the field distributions are symmetrical about the $d$-axis when $i_{q}=0$, irrespective of the value of $i_{d}$. However, when $i_{q} \neq 0$, the field distributions become asymmetrical about the $d$-axis. Therefore, if the magnetic circuit saturates, $d q$-axis cross-coupling will exist, as evidenced from Figs. 6-9, which show the variation of the finite element predicted $\psi_{d}$ and $\psi_{q}$ with the $d$ - and $q$-axis currents. As can be seen both $\psi_{d}$ and $\psi_{q}$, but in particular $\psi_{q}$, are affected by component of current on an orthogonal axis, except in the case of the surface-mounted magnet machine.
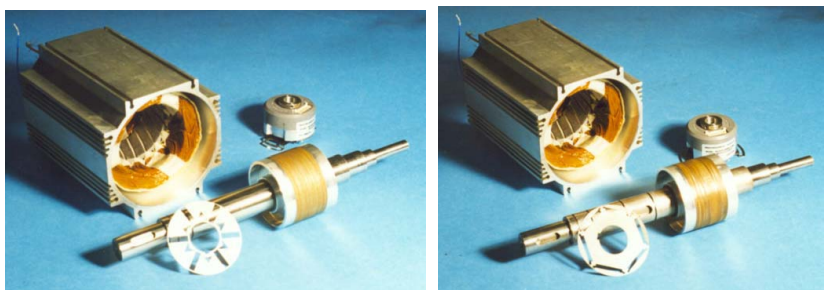

(a) Interior circumferentially magnetized (b) Interior radially magnetized

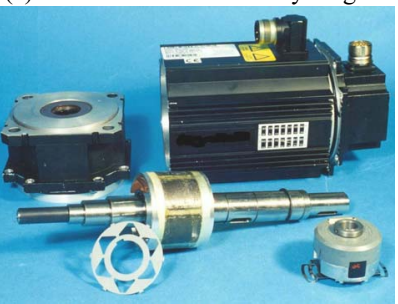

(c) Surface-mounted

Fig.1. Prototype PM BLAC machines.

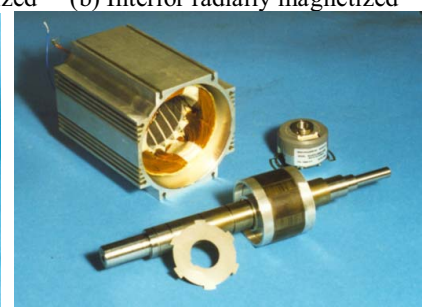

(d) Inset
TABLE I. TABLE I MAIN PARAMETERS OF BLAC MOTORS

\begin{tabular}{|l|c|}
\hline Rated voltage (peak) & $158 \mathrm{~V}$ \\
\hline Rated current (peak) & $4.0 \mathrm{~A}$ \\
\hline Rated power & $0.6 \mathrm{~kW}$ \\
\hline Rated speed & $1000 \mathrm{rpm}$ \\
\hline Rated torque & $4.0 \mathrm{Nm}$ \\
\hline Pole number & 6 \\
\hline Slot number & 18 \\
\hline Stator resistance $\left(R_{s}\right)$ & $6.0 \Omega$ \\
\hline Stator outside diameter & $106.6 \mathrm{~mm}$ \\
\hline Stator core axial length & $32 \mathrm{~mm}$ \\
\hline Magnet remanence $(\mathrm{NdFeB})$ & $1.17 \mathrm{~T}$ \\
\hline
\end{tabular}

From (3), $L_{d}, L_{q}, L_{d q}$ and $L_{q d}$ can be calculated from the $d$ and $q$-axis flux-linkages predicted by finite element analysis:

$$
\begin{aligned}
& L_{q}=\psi_{q}\left(0, i_{q}\right) / i_{q} \\
& L_{q d}=\left[\psi_{q}\left(i_{d}, i_{q}\right)-\psi_{q}\left(0, i_{q}\right)\right] / i_{d} \\
& L_{d}=\left[\psi_{d}\left(i_{d}, 0\right)-\psi_{d}(0,0)\right] / i_{d} \\
& L_{d q}=\left[\psi_{d}\left(i_{d}, i_{q}\right)-\psi_{d}\left(i_{d}, 0\right)\right] / i_{q}
\end{aligned}
$$

where $\psi_{d}(0,0)=\psi_{m}$.
However, as mentioned earlier, only the accuracy to which $L_{q}$ and $L_{q d}$ are predicted will influence the accuracy of the rotor position estimation. However, the predicted variation of $L_{d}$ and $L_{d q}$ is presented for completeness.

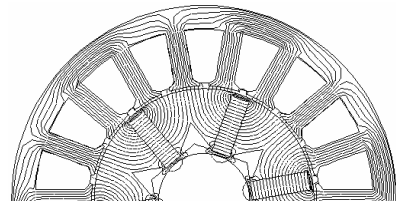

(a) $i_{d}=0 \mathrm{~A}, i_{q}=0 \mathrm{~A}$

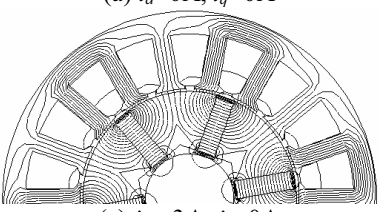

(c) $i_{d}=-3 \mathrm{~A}, i_{q}=0 \mathrm{~A}$

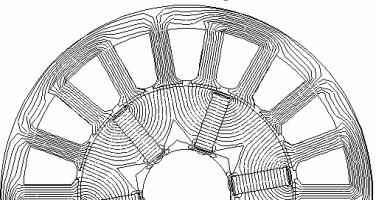

(e) $i_{d}=3 \mathrm{~A}, i_{q}=0 \mathrm{~A}$

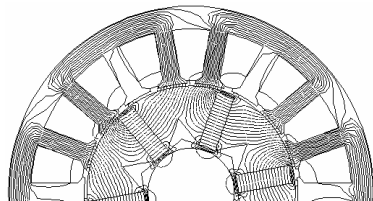

(b) $i_{d}=0 \mathrm{~A}, i_{q}=4 \mathrm{~A}$

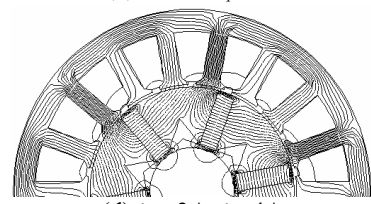

(d) $i_{d}=-3 \mathrm{~A}, i_{q}=4 \mathrm{~A}$

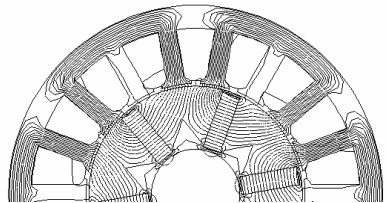

(f) $i_{d}=3 \mathrm{~A}, i_{q}=4 \mathrm{~A}$
Fig. 2. Field distributions for circumferentially magnetized IPM machine.

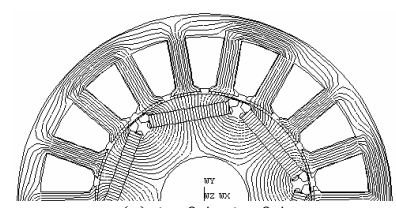

(a) $i_{d}=0 \mathrm{~A}, i_{q}=0 \mathrm{~A}$

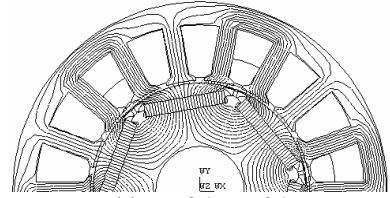

(c) $i_{d}=-3 \mathrm{~A}, i_{q}=0 \mathrm{~A}$

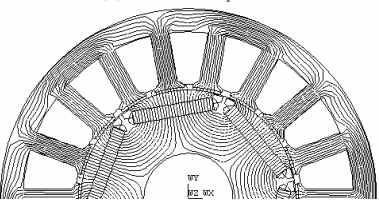

(e) $i_{d}=3 \mathrm{~A}, i_{q}=0 \mathrm{~A}$

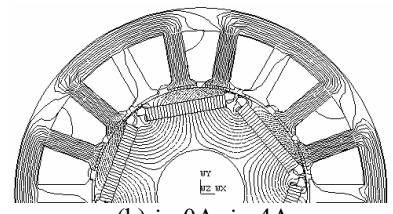

(b) $i_{d}=0 \mathrm{~A}, i_{q}=4 \mathrm{~A}$

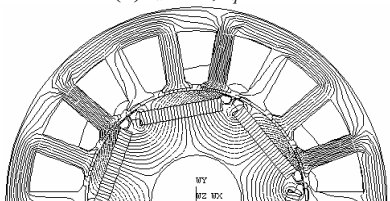

(d) $i_{d}=-3 \mathrm{~A}, i_{q}=4 \mathrm{~A}$

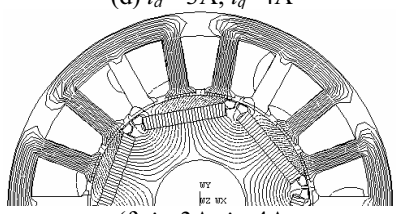

(f) $i_{d}=3 \mathrm{~A}, i_{q}=4 \mathrm{~A}$
Fig. 3. Field distributions for radially magnetized IPM machine.

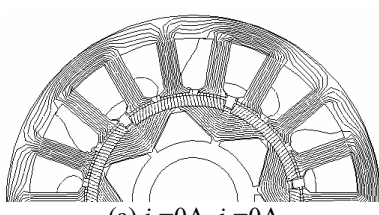

(a) $i_{d}=0 \mathrm{~A}, i_{q}=0 \mathrm{~A}$

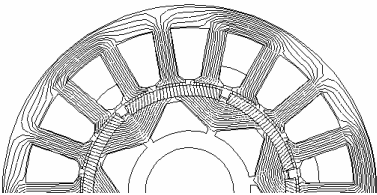

(c) $i_{d}=-3 \mathrm{~A}, i_{q}=0 \mathrm{~A}$

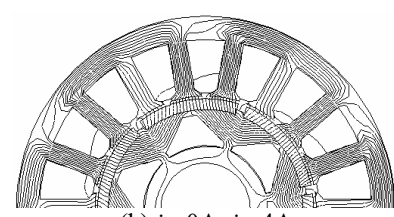

(b) $i_{d}=0 \mathrm{~A}, i_{q}=4 \mathrm{~A}$

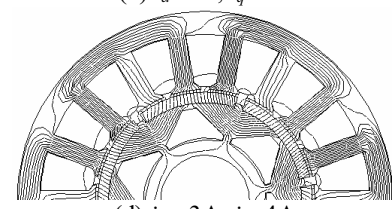

(d) $i_{d}=-3 \mathrm{~A}, i_{q}=4 \mathrm{~A}$ 


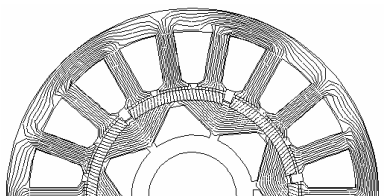

(e) $i_{d}=3 \mathrm{~A}, i_{q}=0 \mathrm{~A}$

Fig. 4. Field distributions for SPM machine.

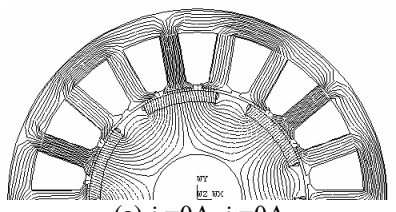

(a) $i_{d}=0 \mathrm{~A}, i_{q}=0 \mathrm{~A}$

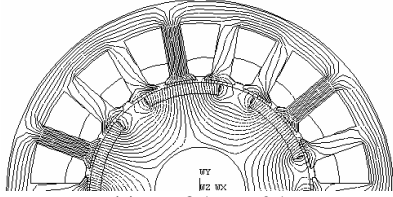

(c) $i_{d}=-3 \mathrm{~A}, i_{q}=0 \mathrm{~A}$

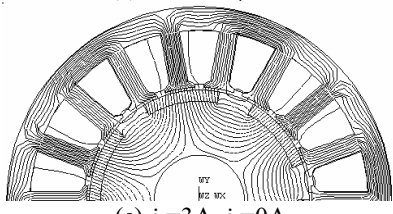

(e) $i_{d}=3 \mathrm{~A}, i_{q}=0 \mathrm{~A}$

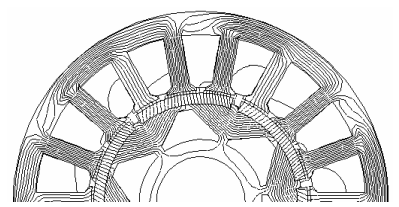

(f) $i_{d}=3 \mathrm{~A}, i_{q}=4 \mathrm{~A}$



(b) $i_{d}=0 \mathrm{~A}, i_{q}=4 \mathrm{~A}$

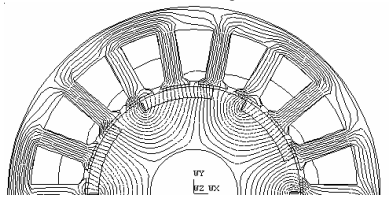

(d) $i_{d}=-3 \mathrm{~A}, i_{q}=4 \mathrm{~A}$

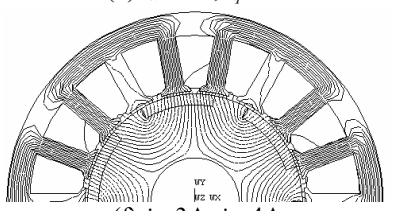

(f) $i_{d}=3 \mathrm{~A}, i_{q}=4 \mathrm{~A}$
Fig. 5. Field distributions for inset PM machine.

The foregoing conclusion is evident from Figs. 10 to 13 . The $d$-axis apparent inductance varies non-linearly with the $d$ axis current $i_{d}$, the $q$-axis apparent inductance also varies nonlinearly with the $q$-axis current $i_{q}$, while $L_{d q}$ and $L_{q d}$ are both functions of $i_{d}$ and $i_{q}$, as a result of magnetic saturation and cross-coupling. $L_{d q}$ and $L_{q d}$ are zero when $i_{q}=0 \mathrm{~A}$. However, $L_{d q}$ and $L_{q d}$ for the surface-mounted magnet rotor machine are very small, as expected. $L_{d q}$ and $L_{q d}$ for the other machine topologies are relatively high since their $q$-axis permeance, and consequently $L_{q}$, is large and the influence of crosscoupling is significant, even for the inset magnet rotor machine which has a low $d$-axis permeance.

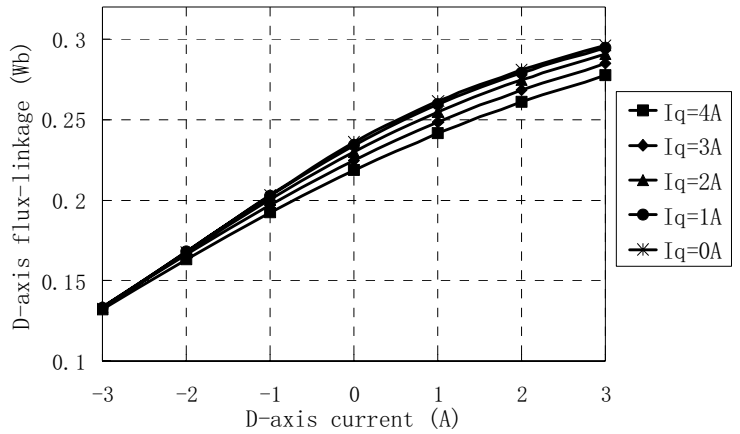

(a) $d$-axis flux-linkage

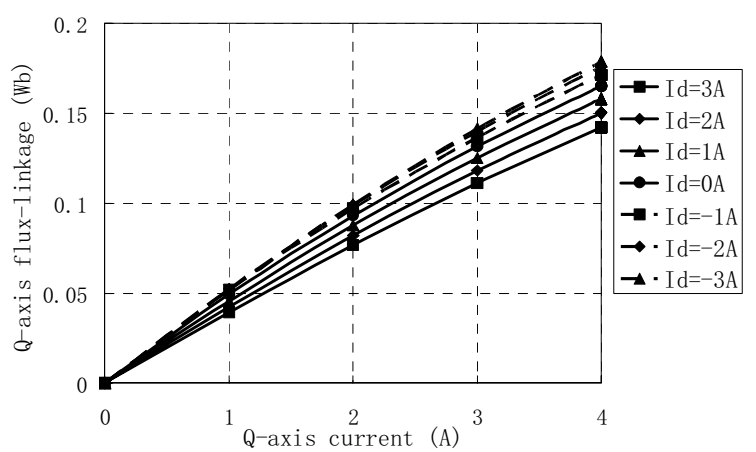

(b) $q$-axis flux-linkage

Fig. 6. Finite element predicted flux-linkage for circumferentially magnetised IPM machine.

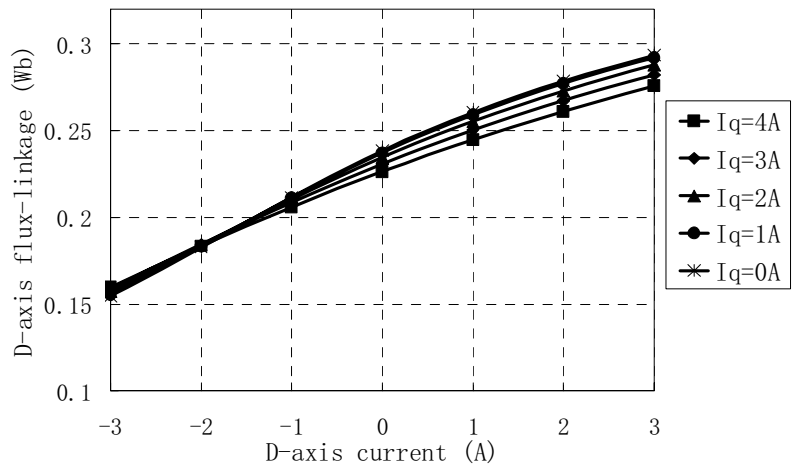

(a) $d$-axis flux-linkage

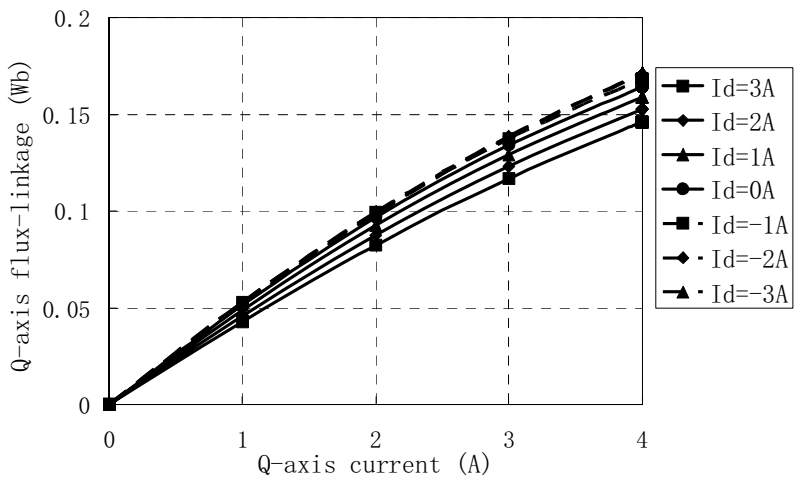

(b) $q$-axis flux-linkage

Fig. 7. Finite element predicted flux-linkage for radially magnetised IPM machine.

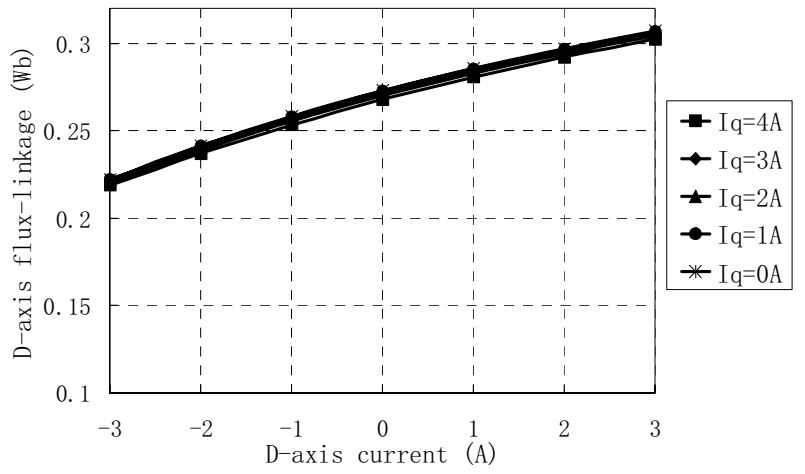

(a) $d$-axis flux-linkage 


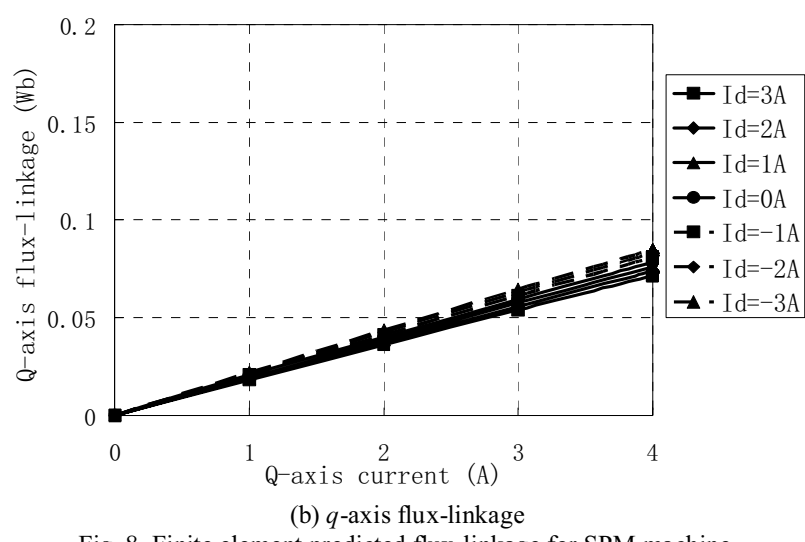

Fig. 8. Finite element predicted flux-linkage for SPM machine.

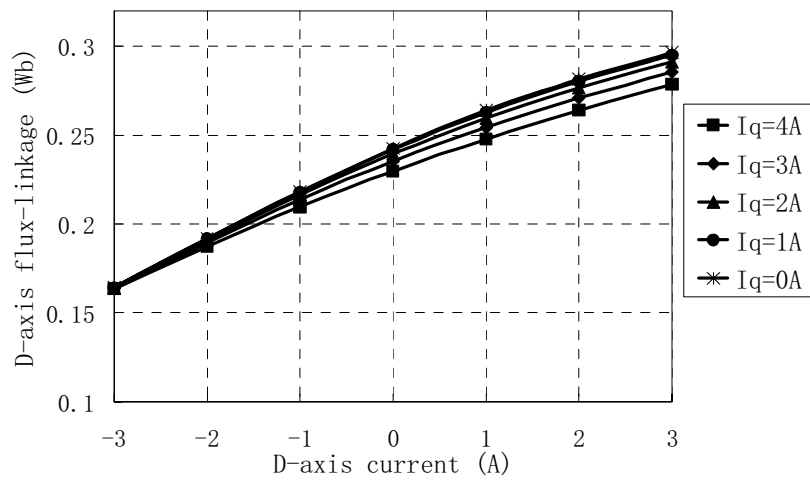

(a) $d$-axis flux-linkage

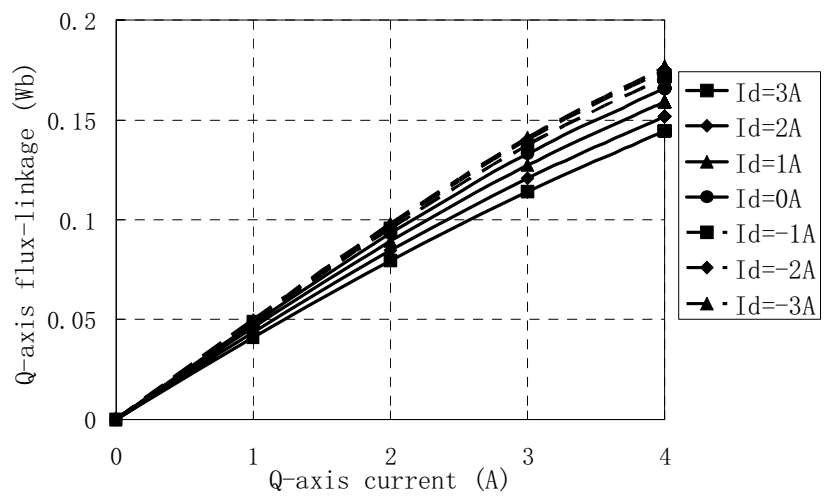

(b) $q$-axis flux-linkage

Fig. 9. Finite element predicted flux-linkage for inset PM machine.

It will be noted from Fig.4 that the SPM machine has airspaces beneath the magnets, primarily to reduce the rotor mass. However, their influence on cross-coupling magnetic saturation and the winding inductances was found to be negligible.

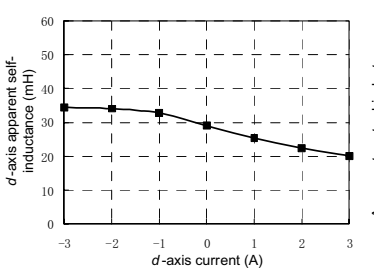

(a) $L_{d}$



(c) $L_{q}$

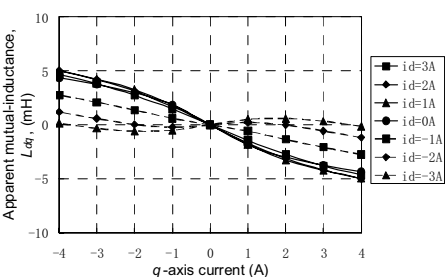

(b) $L_{d q}$

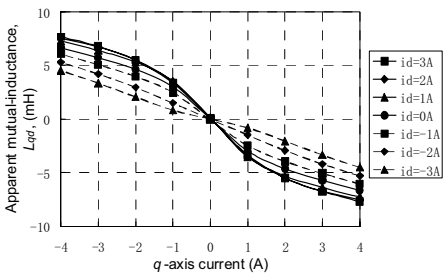

(d) $L_{q d}$
Fig. 10. Finite element calculated apparent self- and mutual-inductances for circumferentially magnetised IPM machine.

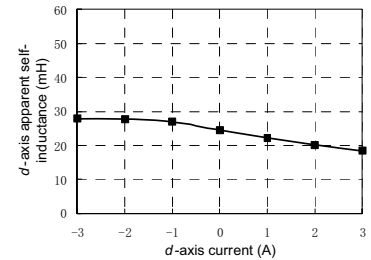

(a) $L_{d}$

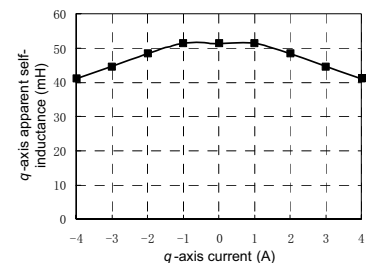

(c) $L_{q}$

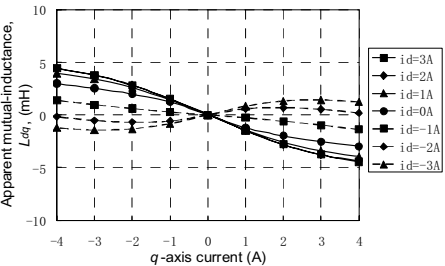

(b) $L_{d q}$

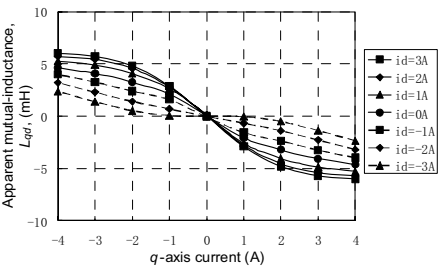

(d) $L_{q d}$

Fig. 11. Finite element calculated apparent self- and mutual-inductances for radially magnetised IPM machine.

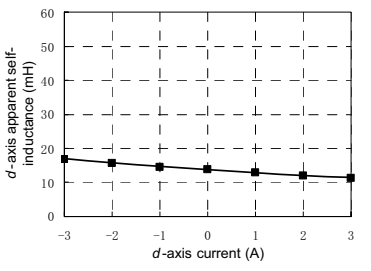

(a) $L_{d}$

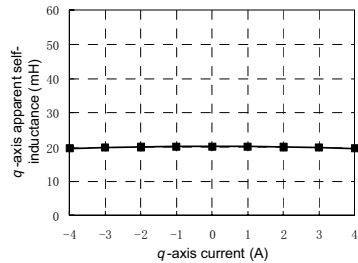

(c) $L_{q}$

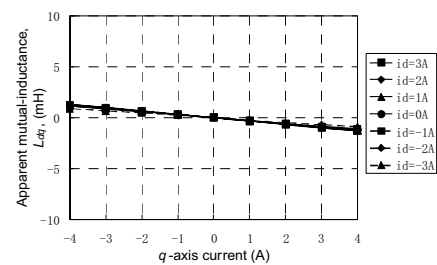

(b) $L_{d q}$

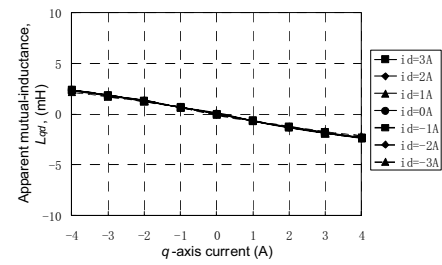

(d) $L_{q d}$
Fig. 12. Finite element calculated apparent self- and mutual-inductances for SPM machine. 


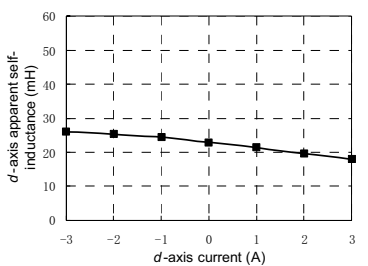

(a) $L_{d}$

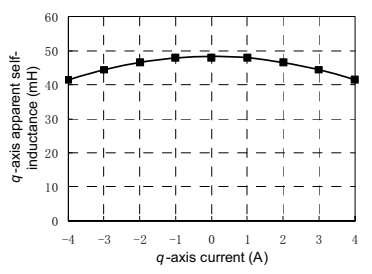

(c) $L_{q}$

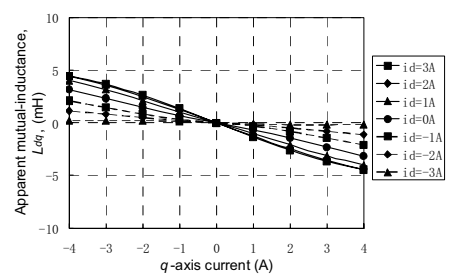

(b) $L_{d q}$

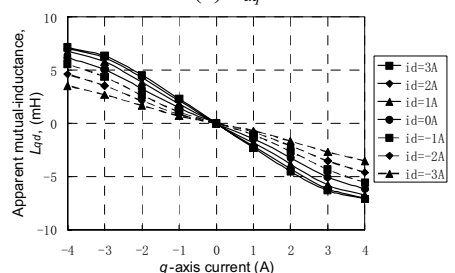

(d) $L_{q d}$
Fig. 13. Finite element calculated apparent self- and mutual-inductances for inset PM machine.

\section{COMPARISON OF ERROR IN ROTOR POSITION ESTIMATION BY VARIOUS EXTENDED BACK-EMF BASED SENSORLESS CONTROL SCHEMES}

Both the conventional and the proposed extended backEMF sensorless schemes have been implemented on a TMS320C31 DSP and the error in the estimated rotor position for the four BLAC machines has been obtained with reference to the actual rotor position measured by a 1024 pulse-perrevolution encoder. The frequency of the $\mathrm{AD}$ sampling rate, the control loop, and the PWM switching were all 5kHz, Fig. 14.

Fig. 15 and Table II compare the measured steady-state error in the estimated rotor position of the four machines, for three extended back-EMF based sensorless control scenarios, viz.

(a) $L_{q}=L_{q N}, L_{q d}=0$, i.e. constant $L_{q}$, and $d q$-axis cross-coupling neglected [1];

(b) $L_{q}=L_{q}\left(i_{q}\right), L_{q d}=0$, i.e. non-linear $L_{q}$, and $d q$-axis crosscoupling neglected [2];

(c) $L_{q}=L_{q}\left(i_{q}\right), L_{q d}=L_{q d}\left(i_{d}, i_{q}\right)$, i.e. non-linear $L_{q}$, and $d q$-axis cross-coupling accounted for.

It can be seen that when $i_{q}=0$, the rotor position estimation error is negligible for all four machines since $L_{q d}=0$ and there is no cross-coupling. When $i_{d}$ is positive, the flux increases, magnetic saturation becomes more prominent, and the error in the estimated rotor position increases. In contrast, when $i_{d}$ is negative, the flux reduces, the magnetic circuit becomes less saturated and the error is reduced. The error is similar irrespective of whether the machine is motoring (positive $i_{q}$ ) or generating (negative $i_{q}$ ). It will also be seen that the surfacemounted magnet machine has a low rotor position estimation error since its $q$-axis reluctance is high and cross-coupling is negligible. Although the inset magnet machine has a low $L_{d}$, $L_{q d}$ is similar to that in the interior magnet machines, since the influence of $q$-axis current is similar. However, when $L_{q}$ is assumed to be constant and $d q$-axis cross-coupling is neglected, the error in the estimated rotor position is large. When the non-linear variation of $L_{q}$ is accounted for but $L_{q d}$ is still neglected, the error is not reduced since the influence of cross-coupling is dominant. By accounting for the influence of cross-coupling, the error in all the machines is reduced significantly, to a similar level to that which results with the surface-mounted magnet machines. However, a small error still exists due to inaccuracies in modeling $L_{q}$ and $L_{q d}$, particularly $L_{q d}$.

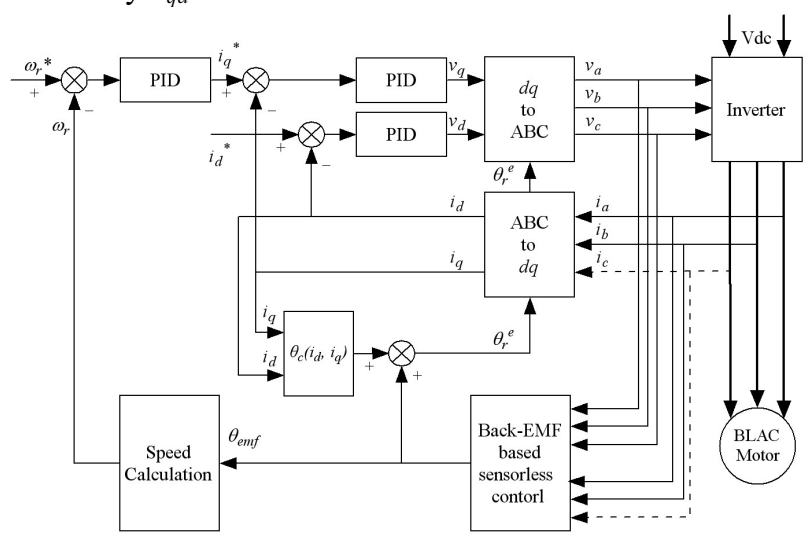

Fig. 14. Extended back-EMF based sensorless scheme with compensation for rotor position error due to cross-coupling.

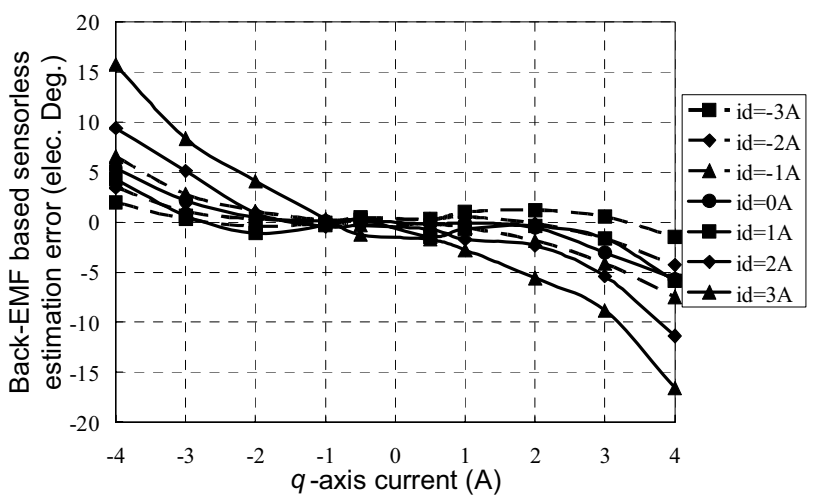

(a) $L_{q}=L_{q N}$

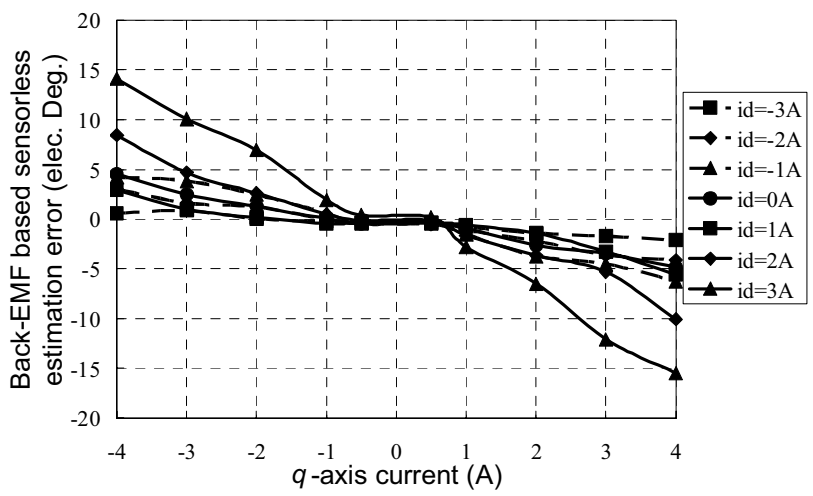

(b) $L_{q}=L_{q}\left(i_{q}\right), L_{q d}=0 \mathrm{mH}$ 


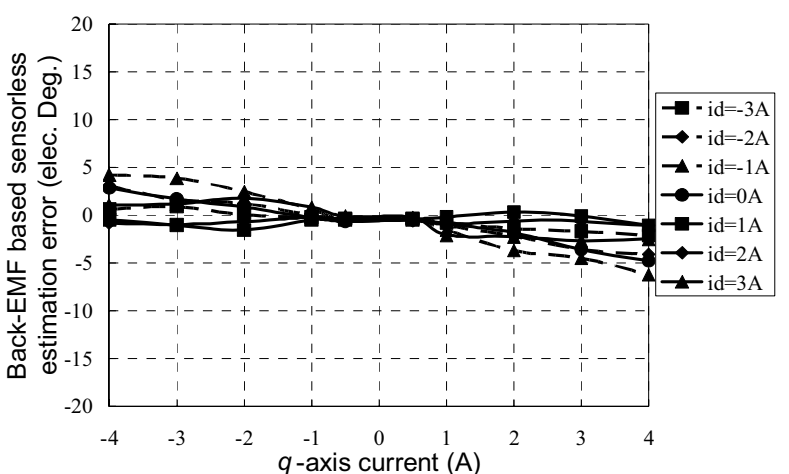

(c) $L_{q}=L_{q}\left(i_{q}\right), L_{q d}=L_{q d}\left(i_{d}, i_{q}\right)$

(i) Interior circumferentially magnetized

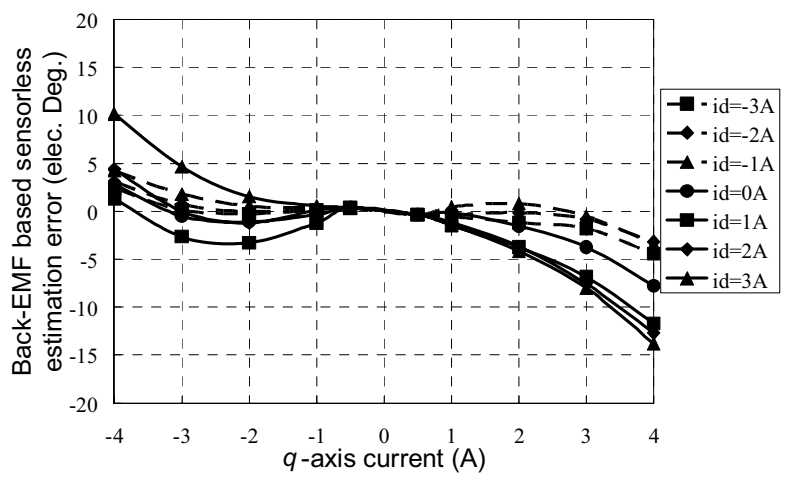

(a) $L_{q}=L_{q N}$

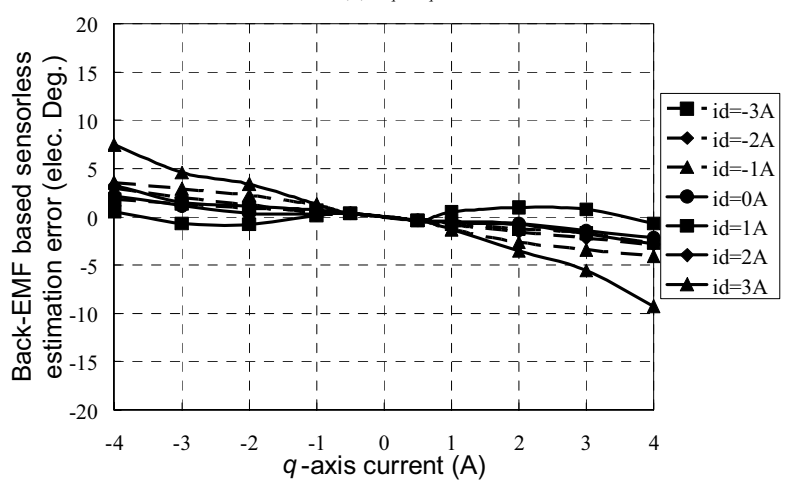

(b) $L_{q}=L_{q}\left(i_{q}\right), L_{q d}=0 \mathrm{mH}$

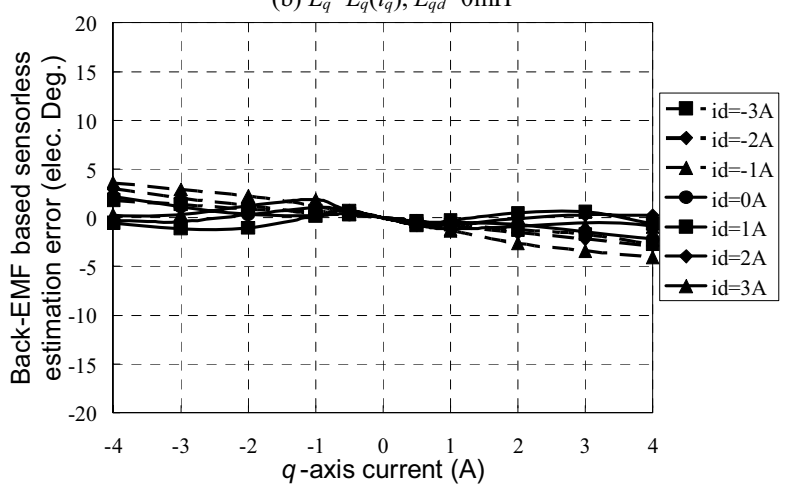

(c) $L_{q}=L_{q}\left(i_{q}\right), L_{q d}=L_{q d}\left(i_{d}, i_{q}\right)$

(ii) Interior radially magnetized

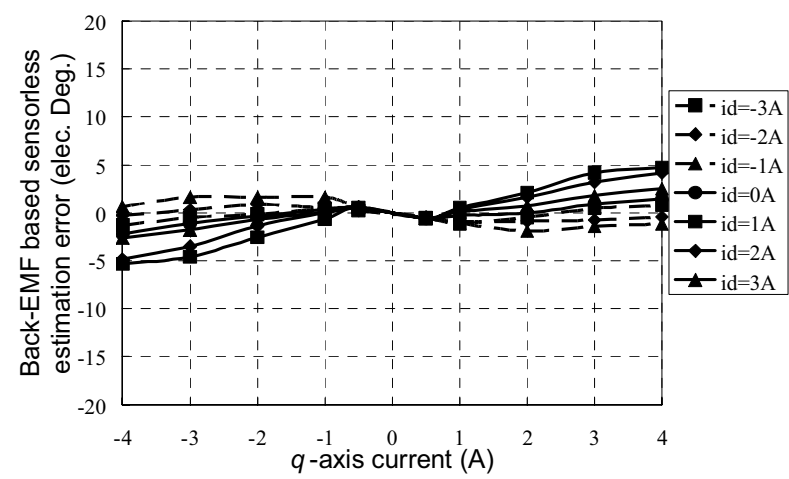

(a) $L_{q}=L_{q N}$

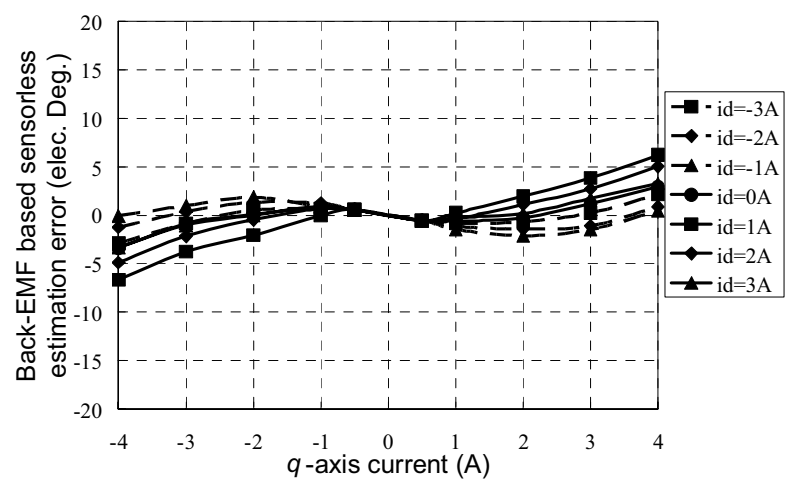

(b) $L_{q}=L_{q}\left(i_{q}\right), L_{q d}=0 \mathrm{mH}$

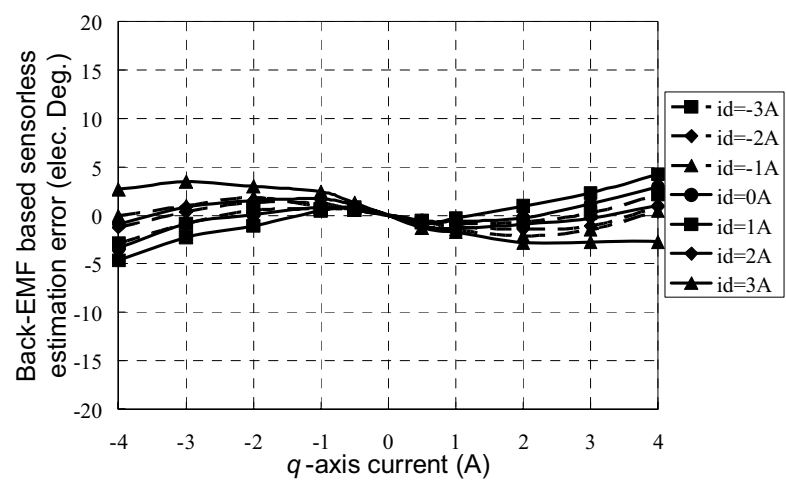

(c) $L_{q}=L_{q}\left(i_{q}\right), L_{q d}=L_{q d}\left(i_{d}, i_{q}\right)$

(iii) Surface-mounted

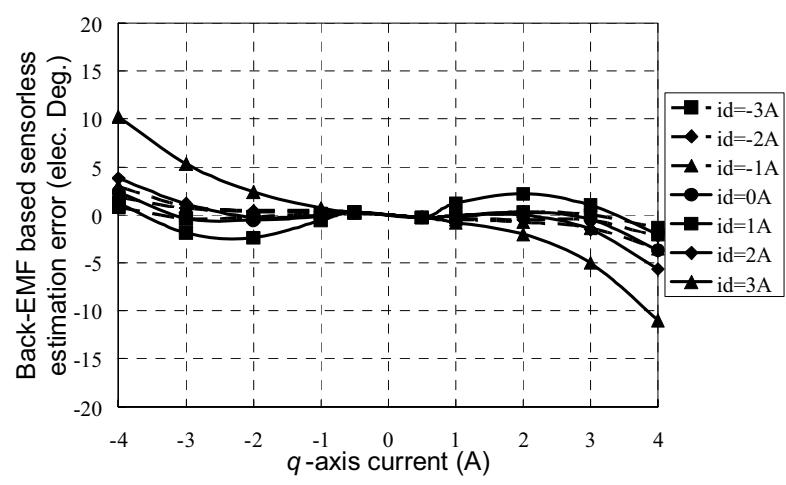

(a) $L_{q}=L_{q N}$ 


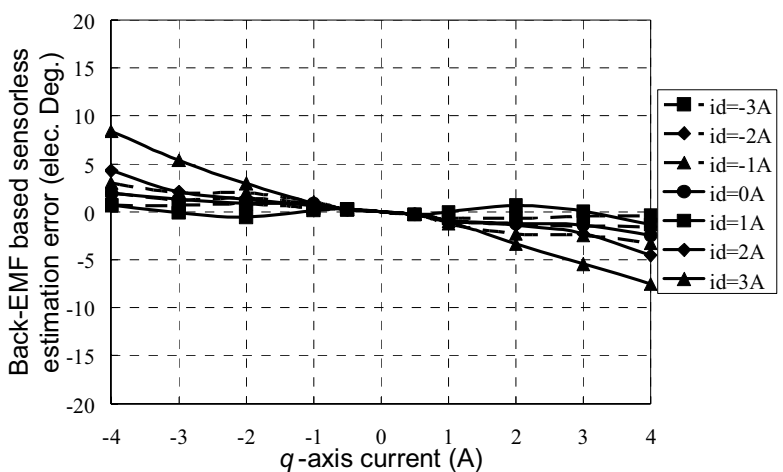

(b) $L_{q}=L_{q}\left(i_{q}\right), L_{q d}=0 \mathrm{mH}$

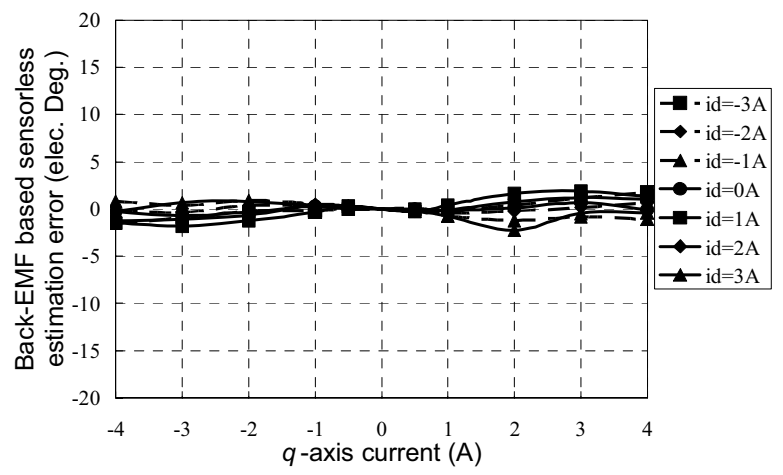

(c) $L_{q}=L_{q}\left(i_{q}\right), L_{q d}=L_{q d}\left(i_{d}, i_{q}\right)$

(iv) Inset

Fig. 15. Variation of measured error in estimated rotor position in different machine topologies with $d$ - and $q$-axis currents.

TABLE II. MEASURED ROTOR POSITION ESTIMATION ERROR FROM EXTENDED EMF BASED SENSORLESS CONTROL

\begin{tabular}{|l|c|c|c|c|}
\hline \multicolumn{1}{|c|}{ RMS error (elec. deg.) } & $\begin{array}{c}\text { Interior } \\
\text { circumferentially } \\
\text { magnetized }\end{array}$ & $\begin{array}{c}\text { Interior } \\
\text { radially } \\
\text { magnetized }\end{array}$ & $\begin{array}{c}\text { Surface- } \\
\text { mounted }\end{array}$ & Inset \\
\hline (a) $L_{q}=L_{q N}, L_{q d}=0$ & 4.3 & 4.9 & 1.8 & 2.5 \\
\hline (b) $L_{q}=L_{q}\left(i_{q}\right), L_{q d}=0$ & 4.4 & 3.5 & 2.0 & 2.2 \\
\hline (c) $L_{q}=L_{q}\left(i_{q}\right), L_{q d}=L_{q d}\left(i_{d}, i_{q}\right)$ & 2.0 & 1.4 & 1.7 & 0.8 \\
\hline
\end{tabular}

\section{CONCLUSIONS}

The influence of the machine topology and $d q$-axis crosscoupling on the rotor position estimation error in the extended back-EMF based sensorless method has been investigated by finite element analyses and validated experimentally. It has been shown that the error is more strongly influenced by the $q$ axis current/permeance than the $d$-axis current/permeance, since a $d$-axis current does not distort the field distribution about the $d$-axis, and that $d q$-axis cross-coupling due to magnetic saturation can significantly affect the accuracy of the rotor position estimation. However, by introducing an apparent mutual winding inductance in the extended backEMF based sensorless method, the error can be reduced significantly.

\section{REFERENCES}

[1] Z. Chen, M. Tomita, S. Koki, and S. Okuma, "An extended electromotive force model for sensorless control of interior permanentmagnet synchronous motors," IEEE Trans. Industrial Electronics, vol.50, no.2, pp. $288-295,2003$

[2] S. Morimoto, K. Kawamoto, M. Sanada, and Y. Takeda, "Sensorless control strategy for salient-pole PMSM based on extended EMF in rotating reference frame," IEEE Trans. Industry Applications, vol.38, no.4, pp. 1054-1061, 2002.

[3] J.H. Jang, S.K. Sul, J.I. Ha, K. Ide, and M. Sawamura, "Sensorless drive of surface-mounted permanent-magnet motor by high-frequency signal injection based on magnetic saliency," IEEE Trans. Industry Applications, vol. 39, no. 4, pp. 1031-1039, 2003.

[4] H. Kim, M. C. Harke, and R. D. Lorenz, "Sensorless control of interior permanent-magnet machine drives with zero-phase lag position estimation," IEEE Trans. Industry Applications, vol.39, no.6, pp. 17261733, 2003.

[5] B. Stumberger, G. Stumberger, D. Dolinar, A. Hamler, and M. Trlep, "Envaluation of saturation and cross-magnetization effects in interior permanent-magnet synchronous motor," IEEE Trans. Industry Applications, vol. 39, no. 5, pp. 1264-1271, 2003.

[6] Y. Li, Z. Q. Zhu, D. Howe, and C. M. Bingham, "Improved rotor position estimation in extended back-EMF based sensorless PM brushless AC drives with magnetic saliency," Proc. IEEE Int. Electric Machines and Drives Conf. 3-5 May 2007, Antalya, Turkey, pp.208-213.

[7] Y.S. Chen, Z.Q. Zhu, and D. Howe, "Design and analysis of PM brushless ac machines with different rotor topologies for fieldweakening operation," Proc. University Power Engineering Conference, (UPEC'99), 14-16 Sept. 1999, Leicester, UK, pp.169-172. 